\title{
Reflections of a
}

Practitioner: Ten Years of

Professional and

Organizational

Development $^{1}$

William H. Bergquist

The Professional School of Psychology

\section{SETTING THE STAGE}

In preparing for the keynote speech at the Joint 1985 National Conference of the Professional and Organizational Development Network and the National Conference for Staff, Program and Organizational Development, I took on the task of retracing the origins of POD, held at the Wingspread Conference Center. In preparing for this speech, I thought I would recover the original files from that conference which included some presentations on the "future" of professional and organizational development in American higher education and then compare the "prophecies" that were made with what has actually happened in the field during the past ten years.

I never found the files from the Wingspread Conference; however, as I was rummaging through my files, I discovered many other files that attracted my attention and delayed my continuing search for the Wingspread file. These files contained printed materials and personal notes from other projects and articles I was working on ten years ago. These materials and notes told me much about myself and my perspectives at that time. When I reflect back on myself ten years ago, I know that I (like most other people) tend to reconstruct a world that is strongly biased by my current perspective. The actual notes I wrote ten years ago provide a more accurate and at times 
surprising picture. In some ways I was smarter ten years ago than I now think I was. In other ways, I was clearly not as wise as I had hoped.

In reflecting on how I have changed over ten years, I began to wonder if the whole field has changed in a similar manner. I recalled an important principle from systems theory suggesting that all or most subsystems tend to echo or mirror the dynamics of the total system. Since I played an important role in the formation of POD and since POD initially had a major influence on my own professional development, then maybe I, as a subsystem of POD, have reflected the major dynamics of POD, the total system. Perhaps some of my issues and life themes are reflected in the organization and in the other individual members of POD and NCSPOD (as an organization that spun off from POD).

I decided in my keynote speech, therefore, to reflect on my own experiences--past, present and future-and to relate these experiences to POD, NCSPOD and the fields of professional and organization development. I ask you, the reader, to reflect in a similar manner on your own experiences as a practitioner. To what extent do the themes I have identified for my own professional life relate to your concerns and transitions?

\section{THEME ONE: CONFORMITY vS. INNOVATION}

In rummaging through my files, I discovered the Masters Thesis that I wrote in 1967 . It was a traditional work-uninteresting, but acceptable to my graduate institution and published in a good disciplinary journal. I also discovered a Masters Thesis written during the previous year (1966). This thesis was not accepted by my committee and was certainly not going to be published in a traditional journal. After almost twenty years, I reread this unacceptable thesis and found it to be interesting, provocative and certainly a much better piece of research than was found in my published thesis.

I looked at both of these works with the painful realization that I still find myself often caught between respectable, acceptable conformity and my more unacceptable creativity and insight. I work within the system, as do most "successful" professional and organization development practitioners, yet in many ways I am seeking to change the system or at least am 
not terribly comfortable living in it.

I keep wondering if I will be found out by those people who hire me. ${ }^{2}$ When will they come to realize that I actually want to transform-or even tear down-the institution that they want me to help patch up ("develop")? Are they, perhaps, just as dissatisfied with the current system as I am? If so, are we playing an unnecessary (or necessary) charade?

The formation of POD was itself a blend of the traditional and nontraditional. The birth of this organization was dependent on the initial support of two men who led major, traditional national associations in American higher education: Dyck Vermillye (American Association for Higher Education) and Gary Quehl (Council of Independent Colleges - then the Council for the Advancement of Small Colleges). Both Vermillye and Quehl are exceptional leaders: visionaries who knew how to work within the system and get the resources that are necessary to bring about nontraditional reform and development.

The fields of professional and organization development are similarly replete with contradictions regarding conformity and innovation. The early programs in faculty development, for instance, were dependent on funds from traditional, corporate foundations (such as the Lilly Endowment and Kellogg Foundation). Later, hard money support became more prevalent. In the latter case, the reform efforts of faculty development practitioners were funded by the very institutions that the practitioners sought to reform. We must look for our support-even our "mentors"-from among men and women who are in positions of power and understandably have their own vested interests and their own blind spots with regard to the need for change and reform in their specific domain.

Yet, POD is a counter-movement. We support innovation, new ideas and change. In the early 1970 s, we offered a critique of the dominant academic culture and its emphasis on research (rather than teaching) (Sanford, 1971; Astin, et al., 1974). Our efforts, however, often have not been successful, precisely because we must rely on the traditional establishment for our resources and because significant change is always a slow and unpredictable process. We are discouraged or at least ambivalent about our efforts and our successes. ${ }^{3}$ 


\section{THEME TWO: ROLE OF THE "ENEMY"}

In reviewing various papers I wrote in the late 1960 s and early 1970 s, I was immediately struck with the role played by the "enemy" in my life. I often seemed to need an adversary in order to give my noble cause some focus and direction. The enemy, however, often seemed to be rather diffuse in character and disposition. The enemy was the government, the dominant academic culture, the traditional universities and the traditional faculty. I wrote with disdain about faculty obsessions regarding publications and academic standards, about limited curricular visions and about the indifference of faculty and administrators in most traditional institutions to teaching and learning issues.

Yet, I also recall a disturbing experience from the early 1970 s that called into question many of my pat ideas about the enemy. I was conducting a workshop for faculty from a prestigious private university. One of the participants spoke about his conservatism, with reference to personal life style as well as politics. He noted that he found great satisfaction sitting alone and very still in his den surrounded by relics of the past. He said that he was a very "closed" person and did not readily disclose personal matters to other people until he knew them for an extended period of time. This statement struck me as poignant and ironic, for it was in many ways the most honest and "open" statement made during the entire workshop. The rest of us had mastered the art of being "open" without actually revealing that which was most intimate and difficult for us to reveal. This "conservative" faculty member took a greater risk than the rest of us in talking about his "closedness" and in violating the norms by being conservative and interpersonally fearful. He was the personification of the "enemy," yet I found myself admiring him much more than my more liberal and liberated faculty colleagues (or myself, for that matter). The enemy had become a person I liked. I fear that this often is the case. A friend of mine, who is a strong political activist, recently expressed a similar sentiment when she noted that she avoids getting to know people who are on opposite sides of the issue from her because then she loses the capacity to be angry about and to take action against these people.

Yet, is there really a need for an enemy? Carl Jung would 
suggest that as we mature as individuals (or even as a society) we become more accommodating to our enemies (our "shadow," in Jungian terms). We welcome the enemy to our home, for we realize that the enemy is a part of us, that we must recognize the enemy that exists within us. In our early years, the enemy is essential to the formation of our identity and our competency, for the enemy usually holds at least part of the truth about ourselves and our world. Our immature values are usually based as much on what we don't believe and don't accept as on what we do believe and do find acceptable.

Am I becoming a bit more mature because I find it harder to find my enemies-or have I simply lost my capacity to get angry and to fight for that which is important in our society? What about POD? Has this organization lost its capacity to fight has it lost its identity, because its old foes seem no longer to be so powerful or so wrong? I wonder.

\section{THEME THREE: INTERDEPENDENCE vS. AUTONOMY}

Several times during my review of old files, I stopped to reflect on a vivid memory of the past. One vivid memory concerned a weeklong workshop in which some of the most successful professional and organizational development practitioners in American higher education met with a group of forty-five faculty members from small colleges throughout the United States. These faculty members were participating in a two year training program to help them become effective as "change agents" and faculty development practitioners on their home campus.

At one point in this weeklong workshop, I distributed a questionnaire about different assumptions on how change takes place in contemporary organizations. I asked each participant to reveal his or her own dominant style and to talk about the implications of this style for his/her work. I recall that the discussion was interesting, though not particularly inspired.

Then one of the more "pushy" participants made an unpardonable request. She asked to see my own scores, as well as the scores of the five other "high powered" consultants and experts. After getting over the initial shock, we all began to offer our own scores in a hesitant and somewhat embarrassed manner. One at a time, each of us revealed that our highest 
score was in the category that builds on the assumption that change rarely occurs in any form (that we simply must wait for the change to occur in an unplanned or "natural" manner). Understandably, the participants were in an uproar. How could we come to this workshop, preaching change and teaching the effective strategies for change, when we don't personally believe that planned change is really likely to occur!

Our initial collective answer to this outrage was somewhat academic. We indicated that after seeing many different efforts at change become unsuccessful, we were hesitant to endorse any general statement that would suggest that a particular formula for change is always or even usually successful. Unfortunately, our "pushy" participant wouldn't let us get away with this answer. She asked us why we were involved in planned change activities, when they are so rarely successful. At this point, the six of us became a bit more honest and the discussion became one of the most meaningful in which I have ever been engaged.

Each of us indicated that we primarily continue our work because of the friendships we have established in the field. Each of my five colleagues had decided to come to this workshop primarily to see and work with the four other people who were going to be there, as well as to make new acquaintances among the forty-five participants.

Thus, relationships seem to be central to our work as professional and organization development practitioners. These concerns were much more important to us than either the content of the workshop or the long-term goals of the change efforts that defined the mission of this training project-we seemed to be speaking in the "other voice" that is often associated with the development of women (Gilligan, 1982).

With this emphasis on relationship, however, I also vividly recall the independent or even competitive sense among us as professional and organization development practitioners. The push toward competition was always subtle and clothed in the best of intentions-yet it was present-along with an equally strong desire for autonomy. Most of us who were moving into consulting (either within one institution or working with multiple institutions) were motivated in part by a fervent desire to get free from the tyrannical constraints of daily regiment, bosses and institutional politics. We wanted to be able to set 
our own standards, do work that we wanted to do and associate with people we found most interesting. We represented the epitome of an American quest for autonomy and profound individualism. ${ }^{4}$ Thus our concern for relationships and community was offset by our desire for autonomy. Or was our search for community at least in part a product of our alltoo-successful acquisition of autonomous life styles?

For the Professional and Organizational Development Network there may be a similar ambivalence about relatedness and autonomy. When several of my colleagues and I first envisioned POD, we (or at least I) saw it as a small intimate network of practitioners in the field who wanted to find support and refreshment in periodic, intensive contact with other people who had made a significant commitment to the field. In many ways this initial image was exclusionary and elitist. The alternative image-which eventually won the day-was of a national association that would draw in many people who were involved in or even peripherally interested in professional and organization development. I suspect that the first image was embedded in a search for community and interdependence. My own brief experience with POD in recent years would lead me to believe that the relational functions of POD are being served for both old and new members through the informal activities of the network's national meetings. I suspect that these informal activities are in fact more satisfying for the old members and may (like my original image) be exclusionary with regard to new members. Nevertheless, POD seems to be responsive to the need for relatedness.

POD is also an expression, however, of autonomy. I still see the model of external consultation being very attractive to many members: the idea of being one's own boss or of avoiding the muck and mire of daily institutional life is very appealing to those who long for autonomy. I see the national conferences being constructed (like most national meetings) around a series of autonomous workshops and activities with each presenter doing his or her own thing. This conference model is at the heart of the American character and certainly is not unique to POD-yet, for POD members, this model stands in contrast to the search for unity, relatedness and community. A POD organization that was structured around community might, for instance, have fewer alternative sessions and many more 
general sessions in which members moved from small group to small group exchanging rather candid views of their own work and life. POD certainly hovers on the edge of this communityI remember an extraordinary evening of folk dancing at Montebello when fifty people seemed to be moving in unison and in joy. I have also witnessed several warm and supportive ceremonies that speak to the issue of community.

What does the future hold for an organization such as POD which is pulled in these different directions? Or am I only imagining this pull because I feel it myself, in my work and life?

\section{THEME FOUR: DREAMS AND REALITY}

In dusting off the old files I found many proposals for new programs. Some of these proposals were funded-I have been quite fortunate in this regard. Many other proposals, however, were not funded (I suspect that the most important unwritten principle of successful grantsmanship is: "Don't be discouraged when you are repeatedly turned down"). As I examined the enacted and rejected proposals and my reactions to them, many strong feelings and memories associated with those feelings arose.

I was pleased to read my initial proposal to AAHE that initiated the Wingspread Conference and led to POD, but read with some pain a wonderful, non-funded proposal for a nationwide comparative study of faculty development in two year and four year colleges and universities. I thoroughly enjoyed reading a proposal for a national experimental college that would be created from scratch each summer, for this dream of mine came to fruition and was even better in practice than on paper. Yet, I also keenly felt the disappointment of reading a proposal for the continuation of this college that was never funded.

It has always been difficult for me to take my dreams to an external funding agency. I hate the idea of walking into the office of a foundation executive with hat-in-hand to convince this person that my fragile and often quite personal idea is worthy of public or corporate support. Dreams are something to protect-something to enact in the privacy of one's own mind or at most among one's friends and colleagues. I enjoyed the experimental college in large part because a small group of faculty and students could individually and collectively enact 
their own dreams regarding a high quality, humane education. Yet, we had to receive a generous grant from a private foundation to conduct this experimental college and had to obtain additional funding (which we were unable to do) if we were to sustain this enactment of our personal dreams.

In so many areas of my life, I must confront the painful collision between dreams and realities. I suspect I am not alone in this experience--especially among my fellow visionaries in POD and NCSPOD. Many adult development theorists would have us believe that we come to terms with the limitations of our dreams during our 40 s transition. I wonder if this is wishful thinking. I anticipate that new dreams will continue to emerge during my $40 \mathrm{~s}, 50 \mathrm{~s}, 60 \mathrm{~s}$ etc.-for as long as I am capable of dreaming and that the pain of intruding reality will not diminish.

I'm certainly not willing to abandon the dreams-yet I know that I can't ignore reality. Furthermore, I know through my own life experiences, as well as my reading of Carl Jung, that one of the emerging developmental tasks in my life concerns the reintegration of the realistic and idealistic aspects of my personality.

Higher education is filled with idealists like me. I find that faculty members and academic administrators will usually score at the extreme end of the Intuition Scale of the Myers-Briggs Type Indicator (Briggs-Myers, 1977), having indicated very little interest in "reality" (high scores on the Sensation Scale). High Intuition scores suggest that a faculty member or administrator is much more interested in the world as it could be than in the work as it actually is. The high Intuition person will begin to rebuild a house in his/her mind within weeks after moving in. The rebuilding may never in fact take place; yet, the Intuitive person's home has usually been rebuilt many times over in his/her mind.

Similarly, for the highly intuitive professional or organization development practitioner the curriculum is rebuilt (at least in mind) every six months or the staff development program is reconceived yet another time by the faculty advisory committee. We are very difficult to work with in part because we seem to be indifferent to data, facts, statistics or direct experience. We argue about the reasons for student attrition without ever going out into the world to ask students why they left. We 
design stately theoretical models without an adequate source of experiential building blocks (Kolb, 1984).

Yet, POD and NCSPOD members are also realists, for we are active and hopefully successful in translating ideas into practice. Our major purpose is helping our idealistic colleagues to be more effective in their professional practices (teaching, advising, governance, research, etc.). We confront faculty and administrators with data-with "facts": "Here are the dominant learning styles of your students;" "Here is the current level of critical thinking among Freshmen at this college;" "Here is the rate of learning for students when each of these instructional methods is applied;" "Here are the expressed needs of faculty with regard to support for research and scholarship at this university." I find myself being the realist in my consulting work with faculty and administrators and live in fear that I will be found out as an unrepentant dreamer and idealist. Do other members of POD and NCSPOD feel the same way at times-or do I simply have a bad grasp on reality (as a very high scoring Intuitive)?

\section{CONCLUDING COMMENTS}

What do these reflections tell me or, if generalizable, tell us about professional and organization development? First, I think that I have learned something from this exercise about conformity and creativity. I must be increasingly attuned to the ways in which I conform (or refuse to conform) and the ways in which I allow or encourage others to exert authority over me. I must be clearer about my own values and goals. What am I willing to compromise and where do I make my stand? This is certainly not a new insight-but it is something about which I must be frequently reminded, given the practical, expedient nature of my work as a professional and organization development consultant.

Second, I should try to appreciate my enemy more fully as I grow older. I must find new reasons for fighting the good fight and must be willing to live in a much more relativistic world, yet, remain committed and clear about my own values and priorities (Perry, 1970). I must remind myself that the "laggards" with regard to any innovation I propose are often the burned-out innovators of ten years before (Rogers, 1982). I 
should honor and use their accumulated wisdom as historians of the past, both successful and unsuccessful. I should also remember that these "laggards" often change places with me regarding other issues; on some matters I become the intransigent laggard who will never change his position, while my conservative colleague becomes the proponent of change.

Third, I find that there is an even greater need for unified, cooperative action in American higher education, as resources continue to diminish while demands for quality and equity continue to increase. Furthermore, I will personally find greater satisfaction in community than in isolation and suspect that other men and women in American higher education share this dream. I do not wish to lose that which is distinctive about me as a person and professional but firmly believe that I can be at least a bit more cooperative and a bit less visible without sacrificing my integrity or identity.

Finally, I wish to continue to dream and to anchor these dreams in the realities that come with collegial discourse. While this essay has afforded me the opportunity for only an uninterrupted monologue, I thoroughly enjoyed the opportunity to discuss these ideas in person at the POD/NCSPOD conference and look forward to communicating with colleagues in the future about these reflections. Thank you for allowing me the opportunity to address you at the conference and in this essay.

\section{REFERENCES}

Astin, A., et. al. (1974). Faculty Development in a Time of Retrenchment. New York: Change Magazine.

Bellah, R., et. al. (1985). Habits of the Heart. Berkeley: University of California Press.

Bergquist, W.H. and Phillips, S.R. (1974). A Handbook for Faculty Development Volume One. Washington, D.C.: Council of Independent Colleges.

Burke, W.W. (1982). Organization Development: Principles and Practices. Boston: Little, Brown and Co.

Gilligan, C. (1982). In a Different Voice. Cambridge, MA: Harvard University Press.

Kolb, D. (1984). Experiential Learning. New York: Prentice-Hall.

Perry, W. (1970). Forms of Intellectual and Ethical Development in the College Years. New York: Holt, Rinehart and Winston. 
Rogers, E. (1982). Diffusion of Innovation. Third Edition. New York: Free Press.

Sanford, N. (1971, winter). Academic Culture and the Teacher's Development. Soundings.

\section{NOTES}

1. This paper was presented as the keynote address for the 1985 POD Network-NCSPOD joint conference, Delavan, Wisconsin.

2. Warner Burke (1982, pp. 10-11) distinguishs between the "normative" and "contingent" camps of organization development. The former acknowledges that a "change agent" will inevitably be promoting a specific change, hence must acknowledge his/her own value system and its influence on one's client. The latter camp argues that professional and organization development practitioners can be value free and that they are in the business of facilitating the changes desired by their client rather than the changes that they wish to take place. Yet, like Burke, we must ask ourselves if, in fact, we can be "valuefree"-especially with regard to something that we care about as higher education. When I worry about being "found out," I am, in part, worrying about my "contingent" stance being discovered as a "normative" stance.

3. In a moment of painful candor, Warner Burke (1982, pp. 371) has noted that "organization development is not . . . a revolutionary movement. Change in organizations most often is evolutionary, coming about slowly and by degrees; compromises occur; the original change goal is no longer feasible; people move to other positions or organizations just when change was in the making; changes in the environment cause setbacks, and our OD effort is temporarily if not permanently shelved; the diagnosis is too negative for the boss to handle and we must temper or delay matters somewhat; the boss is on board but key subordinates are not; and so on ... In some instances ... OD may be nothing more than a cooling-out process, so that the change the boss wants is no longer resisted." Similarly, in the case of professional development, we are often caught in the position of having to compromise our visions and "negotiating with the devil" in order to get anything of substance done.

4. See the brilliant and provocative analysis of the American character by Robert Bellah and his colleagues, Habits of the Heart, Berkeley: University of California Press, 1985. 